\title{
Short communication: Vitamin D status and responses in dairy cows naturally infected with Mycobacterium avium ssp. paratuberculosis
}

\author{
J. R. Stabel, ${ }^{*}$ T. A. Reinhardt, and R. J. Hempel \\ USDA-Agricultural Research Service, National Animal Disease Center, Ames, IA 50010
}

\begin{abstract}
Serum samples were obtained from Holstein dairy control cows and cows naturally infected with Mycobacterium avium ssp. paratuberculosis (MAP) to evaluate the effects of disease status on serum 25-hydroxyvitamin $\mathrm{D}_{3}\left(25 \mathrm{OHD}_{3}\right)$ levels. Disease status was stratified for infected cows into asymptomatic, subclinical infection $(\mathrm{n}=25)$, and cows demonstrating clinical signs ( $\mathrm{n}$ $=20)$, along with noninfected control $(\mathrm{n}=12)$ cows for comparison. In addition, portions of the ileocecal valve were taken from a subsample of cows $(n=5$ per treatment group) at necropsy and processed for RNA sequencing gene transcription studies. Genes associated with vitamin $\mathrm{D}$ metabolism were queried to determine any association between infection and gene expression. Serum $25 \mathrm{OHD}_{3}$ levels were significantly lower in cows in the clinical stage of disease compared with either cows in the subclinical stage and noninfected control cows. Differential expression for genes associated with the vitamin D pathway such as CYP27A1, CYP27B1, vitamin D-binding protein $(D B P)$, and $I F N G$ was dependent upon infection status. An upregulation of CYP27A1 was noted for cows in subclinical status, whereas $C Y P 27 B 1$ expression was enhanced for clinical cows. Increased expression of vitamin D-binding protein was observed for infected cattle, regardless of infection status. In summary, decreases in circulating $25 \mathrm{OHD}_{3}$ for animals with clinical disease may suggest that these cows have reduced innate immune responses, thereby influencing the ability of animals to fight infection.
\end{abstract}

Key words: Johne's disease, paratuberculosis, dairy cattle, vitamin D

\section{Short Communication}

Vitamin D is an immunomodulator of both innate and adaptive immunity. The active form of vitamin D,

Received June 19, 2018.

Accepted October 26, 2018.

*Corresponding author: judy.stabel@ars.usda.gov 1,25-dihydroxyvitamin $\mathrm{D}_{3}\left[\mathbf{1}, \mathbf{2 5}(\mathbf{O H})_{2} \mathrm{D}_{3}\right]$, plays a role in activation of macrophages, resulting in increased killing of intracellular pathogens through toll-like receptor-2 and increased expression of cathelicidin (Liu et al., 2006, 2007). In dairy cattle, intramammary infusion with $100 \mu \mathrm{g}$ of 25 -hydroxyvitaminD $\mathrm{D}_{3}\left(\mathbf{2 5 O H D}_{3}\right)$ has been associated with enhanced clearance of Streptococcus uberis from the mammary gland, along with further correlations with reduced clinical signs of mastitis (Lippolis et al., 2011). No differences in serum $25 \mathrm{OHD}_{3}$ were observed in treated cows, suggesting that effects were localized to the mammary gland and likely resulted in increased $1,25(\mathrm{OH})_{2} \mathrm{D}_{3}$ by macrophages present in the infected quarters. In vitro studies demonstrated that

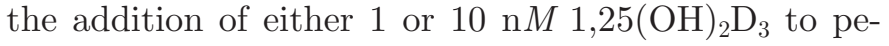
ripheral blood mononuclear cells isolated from cattle infected with Mycobacterium bovis reduced production of antigen-specific IFN- $\gamma$, yet increased nitric oxide production (Waters et al., 2001). Stimulation of peripheral blood mononuclear cells with $M$. bovis purified protein derivative $(10 \mu \mathrm{g} / \mathrm{mL})$ for $24 \mathrm{~h}$ upon isolation from calves vaccinated for $M$. bovis resulted in upregulation of $C Y{ }^{2} 27 B 1$ and IFNG genes. However, concomitant addition of both $1,25(\mathrm{OH})_{2} \mathrm{D}_{3}$ and $M$. bovis purified protein derivative to cell cultures resulted in downregulation of $I F N G$ and $I L 17 F$ gene expression (Nelson et al., 2011).

Vitamin $\mathrm{D}_{3}$ must undergo dual hydroxylation in the liver and kidney to become the active form, $1,25(\mathrm{OH})_{2} \mathrm{D}_{3}$. Hosts that are unable to perform efficient conversion of dietary vitamin $\mathrm{D}_{3}$ to the active form may have reduced immune function. Little work has been done to demonstrate a link between circulating levels of vitamin D and cattle with paratuberculosis. However, it is possible that vitamin D plays a role in regulation and mediation of chronic inflammatory responses associated with Mycobacterium avium ssp. paratuberculosis (MAP) infection. The present study was designed to evaluate effects of disease status on serum levels of $25 \mathrm{OHD}_{3}$ and expression of vitamin D genes in the target tissue of MAP colonization.

Holstein dairy cows ranged in age from 4 to $9 \mathrm{yr}$ in our study and were placed in 3 groups consisting of 
noninfected control cows $(\mathrm{n}=12$; age $3.9 \pm 0.7 \mathrm{yr})$, cows naturally infected with MAP but asymptomatic (subclinical; $\mathrm{n}=25$; age $5.3 \pm 0.4 \mathrm{yr}$ ), and cows naturally infected in the clinical stage of disease $(\mathrm{n}=20$; age $4.8 \pm 0.3 \mathrm{yr}$ ). All cows were maintained on site with separate housing for infected and noninfected control cows and ranged from early to late lactation within treatment group. Cows were fed a TMR consisting of corn silage, chopped hay, cracked corn, and soybean meal with estimated intake of 40,000 IU of vitamin $\mathrm{D} / \mathrm{d}$. The stage of infection was determined by fecal shedding of MAP, antigen-specific IFN- $\gamma$ secretion (Bovigam, ThermoFisher, Waltham, MA), and specific antibody response to MAP (Herdchek, IDEXX Laboratories, Westbrook, ME; Khalifeh and Stabel, 2013). Infection was monitored by bacteriologic culture for the fecal shedding of MAP by standard methods (Stabel, 1997). In the clinical group, MAP shedding exceeded $100 \mathrm{cfu} / \mathrm{g}$ of feces and animals demonstrated weight loss and intermittent diarrhea. In the subclinical group, MAP shedding was less than $10 \mathrm{cfu} / \mathrm{g}$ of feces and animals were asymptomatic. The noninfected control cows were characterized by repeated negative fecal culture performed semiannually over a period of 3 to $5 \mathrm{yr}$. In addition, these animals were negative for production of antibodies specific for MAP and antigen-specific IFN- $\gamma$ responses. Infection status of the cows was also characterized by quantitative culture of MAP, histopathologic scoring of acid-fast stain, and lesion severity in the ileocecal valve (Table 1). All animal related procedures, such as euthanasia and necropsy, were approved by the
Institutional Animal Care and Use Committee (National Animal Disease Center, Ames, IA).

Serum samples were collected from cows while they were housed on-site at the National Animal Disease Center as part of routine screening of infection status. Total $25 \mathrm{OHD}_{3}$ equivalents were quantified by RIA after extraction of serum with acetonitrile. Serum $(50 \mu \mathrm{L})$ was added to $500 \mu \mathrm{L}$ of acetonitrile and mixed carefully. Then, $25 \mu \mathrm{L}$ of the extracted sample was combined with an equal volume of radioiodinated $25 \mathrm{OHD}_{3}$ (Diasorin Inc., Stillwater, MN; 10,000 counts/min in $25 \mu \mathrm{L}$ of ethanol with $0.01 \mathrm{M}$ sodium phosphate). The samples were then centrifuged at 2,000 $\times g$ for $10 \mathrm{~min}$ at room temperature, and the pellet was discarded. The RIA then was conducted as described by Hollis et al. (1993). Serum vitamin concentration was analyzed by ANOVA using PROC MIXED procedures of SAS (version 9.3, SAS Institute Inc., Cary, NC), with TukeyKramer post-hoc test for comparison of means.

The RNA was extracted from ileocecal valve tissues obtained at necropsy from noninfected control cows (n $=5$ ) and naturally infected cows in the subclinical (n $=5)$ and clinical $(\mathrm{n}=5)$ stages of disease as previously described (Hempel et al., 2016). Approximately $200 \mathrm{mg}$ of snap-frozen tissue was placed into $2 \mathrm{~mL}$ of RNAlater-ICE (Life Technologies, Carlsbad, CA) and stored at $-80^{\circ} \mathrm{C}$ according to manufacturer's protocol (https: / / www.thermofisher.com/order/catalog/product/ AM7030). Approximately $50 \mathrm{mg}$ of tissue was removed from RNAlater-ICE and homogenized in gentleMACS M tubes (Miltenyi Biotec, Bergisch Gladbach, Germa-

Table 1. Tissue results for cows in different Mycobacterium avium ssp. paratuberculosis (MAP) infection status $^{1}$

\begin{tabular}{llccc}
\hline $\begin{array}{l}\text { Infection } \\
\text { status }\end{array}$ & $\begin{array}{l}\text { Cow } \\
\text { identificaton }\end{array}$ & $\begin{array}{c}\text { MAP, cfu/g } \\
\text { of tissue }\end{array}$ & $\begin{array}{c}\text { MAP, cfu/g } \\
\text { of feces }\end{array}$ & $\begin{array}{c}\text { Lesion } \\
\text { scores }\end{array}$ \\
\hline Control & 0017 & 0 & 0 & 0 \\
& 0018 & 0 & 0 & 0 \\
& 0441 & 0 & 0 & 0 \\
Subclinical & 0490 & 0 & 0 & 0 \\
& 8102 & 0 & 0 & 0 \\
& 0030 & 0 & 0 & 0 \\
Clinical & 0072 & 0 & 0 & 0 \\
& 0787 & 750 & 0 & 0 \\
& 1061 & 425 & 0 & 4 \\
& 1145 & 0 & TNTC & 3 \\
& 0010 & TNTC & TNTC & 3 \\
& 0035 & TNTC & TNTC & 3 \\
\hline
\end{tabular}

${ }^{1}$ In addition to tissue results above, stage of infection was determined by fecal shedding of MAP, antigenspecific IFN- $\gamma$ secretion, and specific antibody response to MAP.

${ }^{2} \mathrm{TNTC}=$ too numerous to count. 
ny) containing cold RLT Plus buffer (Qiagen, Hilden, Germany) with $\beta$-mercaptoethanol (diluted 1:100). After centrifugation at $2,000 \times g$ for $5 \mathrm{~min}$ at $4^{\circ} \mathrm{C}$ to remove tissue debris, the supernatant was removed and used for RNA extraction using the RNeasy Mini Plus Kit (Qiagen). Approximately $4 \mu \mathrm{g}$ of total RNA from each sample was used to create an RNA sequencing library using the mRNA Seq Single Read Library preparation kit per manufacturer's instructions (https:// www.illumina.com/products/by-type/sequencing-kits/ library-prep-kits/truseq-stranded-mrna.html; Illumina Inc., San Diego, CA). Complementary DNA libraries were sequenced using Illumina sequencing technology (Illumina HiSeq 2500) in 5 lanes of the sequencing flow cell. Libraries were prepared and sequenced at the Iowa State University DNA Facility (Ames, IA). Sequences were analyzed for quality by FastQC (version 0.10.1; http://www.bioinformatics.babraham.ac.uk/projects/ fastqc/) and aligned to the Bos taurus genome as previously described (Hempel et al., 2016). Trimmed reads were aligned to the Bos taurus genome (Ensembl UMD 3.1, version 70; Elsik et al., 2016) with TopHat splice junction mapper (version 2.0.11; Kim et al., 2013) using the Bowtie method (version 2.2.2; Langmead and Salzberg, 2012) and sorted using SAMtools (version 0.1.19; Li et al., 2009; Anders et al., 2014) to obtain raw counts per transcript. Differential expression analysis was performed on the raw counts in the $\mathrm{R}$ statistical programming environment (R Core Team, 2016) using the EdgeR (version 3.8.6) Bioconductor package (Robinson and Smyth, 2007; Robinson et al., 2010). All the libraries were sequenced within 5 lanes of 1 Illumina flow cell, generating an average of 122.2 million reads per lane. The average number of reads per sample was 40.7 million (Hempel et al., 2016). Alignment of the RNA sequencing reads to the Bos taurus genome (Ensembl UMD 3.1) yielded a mean of 36.9 million reads per sequenced library. Genes $(\mathrm{n}=36)$ associated with vitamin $\mathrm{D}$ pathways were parsed, and those that were differentially expressed between treatment groups (control vs. subclinical; control vs. clinical; and subclinical vs. clinical) are discussed.

Serum $25 \mathrm{OHD}_{3}$ levels were significantly $(P<0.01)$ lower for clinical cows compared with the other treatment groups (Figure 1). Serum obtained from a subset of these same cattle ( $n=10$ per treatment group) just before necropsy demonstrated further reductions in serum $25(\mathrm{OH})$-vitamin $\mathrm{D}_{3}$, with an additional $20 \%$ drop observed for clinical $(58.8 \pm 6.7$ vs. $46.3 \pm 7.3)$ cows but not controls or subclinical cows $(97 \pm 5.1$ vs. 103.7 \pm 11.4 and $95.2 \pm 4.6$ vs. $84.6 \pm 8.2$, respectively). Antigen-stimulated IFN- $\gamma$ responses were higher $(P<$
0.01) for subclinical and clinical cows compared with noninfected controls (Figure 2).

Genes associated with the vitamin D pathway that demonstrated differential expression between one or more treatment groups are shown in Table 2 . Interferon- $\gamma$ expression was upregulated in tissue of clinical cows versus control $(P<0.04)$ and clinical cows versus subclinical cows $(P<0.03)$. We found no difference in $I F N G$ gene expression between subclinical cows and control cows. Expression of CYP27A1 and $C Y P 27 B 1,2$ genes that control hydroxylation of vita$\min \mathrm{D}_{3}$, were dissimilar in their responses. Gene expression of CYP27A1 was not different for clinical cows but was downregulated $(P<0.05)$ for subclinical cows when compared with controls. In contrast, expression of $C Y$ P27B1 was upregulated for clinical cows compared with subclinical cows $(P<0.04)$. Interestingly, vitamin D-binding protein $(V D B P)$ was upregulated in both clinical and subclinical cows compared with control cows $(P<0.01$ and $P<0.03$, respectively). We noted no differences in gene expression of $C Y P 2 R 1$ or $V D R$ in the tissue for these cows regardless of treatment group (data not shown).

In the present study, reduced levels of serum $25 \mathrm{OHD}_{3}$ were associated with cattle in the clinical stage of

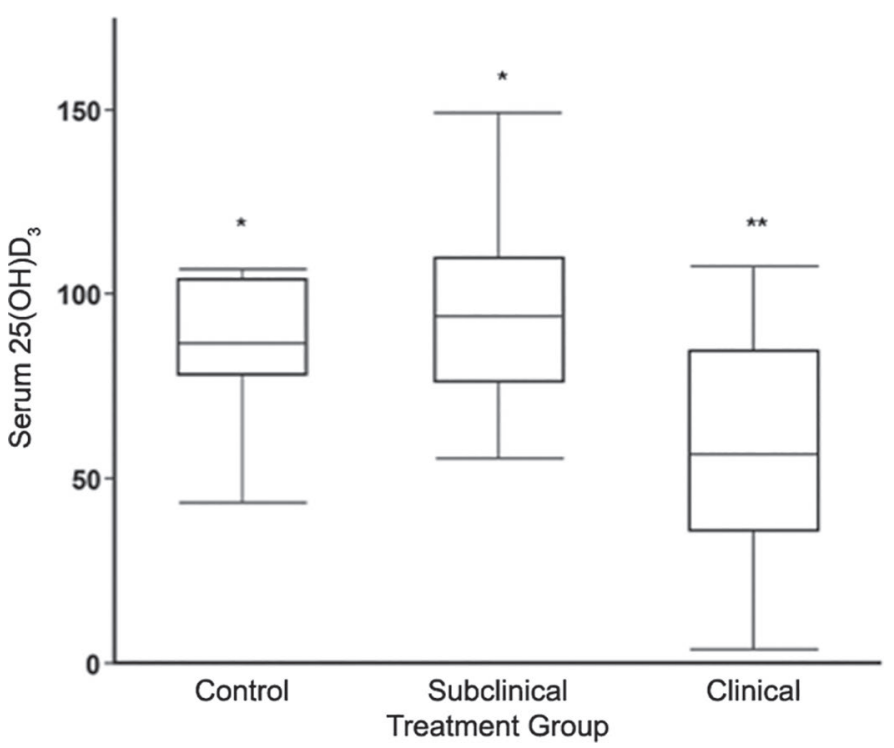

Figure 1. Serum 25(OH)-vitamin $\mathrm{D}_{3}$ concentrations $(\mathrm{ng} / \mathrm{mL})$ for dairy cows in different states of Mycobacterium avium ssp. paratuberculosis infection. Cows were stratified into noninfected control cows and naturally infected cattle in subclinical or clinical infection status. Boxplots shown represent the upper and lower quartiles of the data with a line representing the median value. Whiskers on the plots represent the maximum and minimum values in the dataset. Means with different symbols $(*, * *)$ are different $(P<0.01)$. 
Johne's disease. Neonatal calves are most susceptible to MAP infection, generally through exposure to MAP shed into the feces or milk by infected dams. Although neonates are born with very low levels of vitamin $D_{3}$, they can rapidly achieve adequate nutritional status through proper ingestion of colostrum and milk replacer. If proper nutritional management is not followed, deficiencies might contribute to the susceptibility to MAP infection; however, that was beyond the scope of the current study. Under normal husbandry, adult dairy cattle receive ample vitamin $\mathrm{D}_{3}$ in their diets, averaging 800 to $2,000 \mathrm{IU} / \mathrm{kg}$, depending upon stage of lactation (NRC, 2001), suggesting that intake of vitamin $\mathrm{D}_{3}$ is not a contributing issue to the effect on disease state. Serum $25 \mathrm{OHD}_{3}$ is the major form of vitamin $\mathrm{D}_{3}$ in the serum, ranging from 53 to $82 \mathrm{ng} / \mathrm{mL}$, and is measured to assess vitamin D status (Prietl et al., 2013; Nelson et al., 2016). A previous field report demonstrated an inverse correlation between serum $25 \mathrm{OHD}_{3}$ concentrations and serum MAP antibody in dairy cattle, with serum $25 \mathrm{OHD}_{3}$ averaging $5.3 \mathrm{ng} /$ $\mathrm{mL}$ lower in MAP antibody-positive cows (Sorge et al., 2013). Cattle in the present study were characterized by multiple diagnostic tests including serum antibody, IFN- $\gamma$ release, and fecal shedding and, therefore, were able to be grouped more definitively into subcategories of subclinical and clinical infection. Cows in the clini-

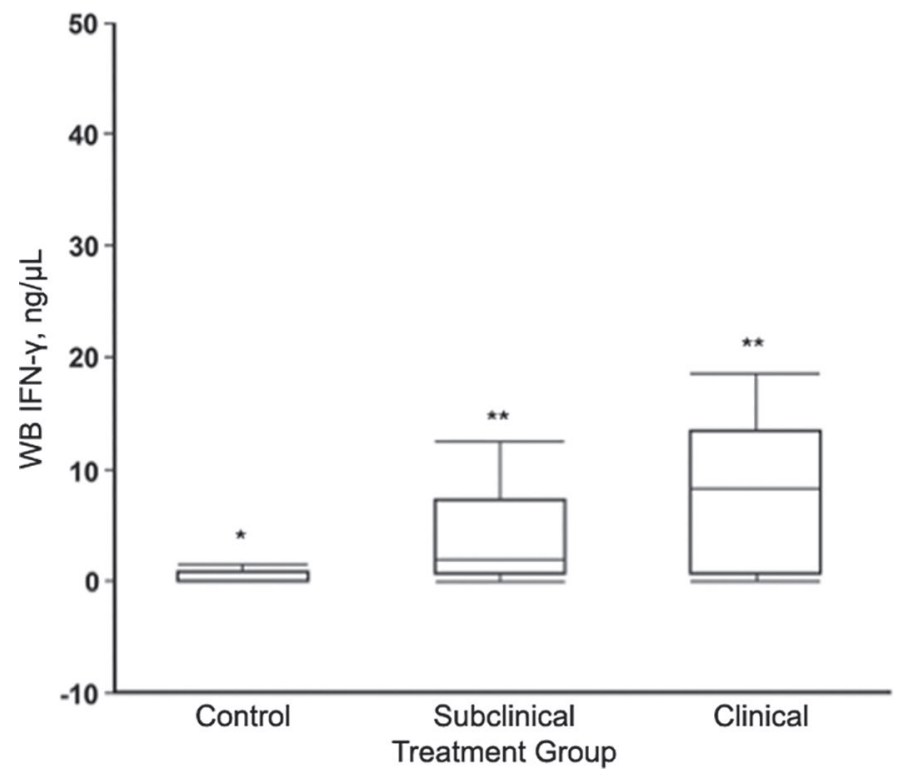

Figure 2. Whole blood (WB) IFN- $\gamma(\mathrm{ng} / \mu \mathrm{L})$ for dairy cows in different states of Mycobacterium avium ssp. paratuberculosis infection. Cows were stratified into noninfected control cows and naturally infected cattle in either subclinical or clinical infection status. Boxplots shown represent the upper and lower quartiles of the data with a line representing the median value. Whiskers on the plots represent the maximum and minimum values in the dataset. Means with different symbols $(*, * *)$ are different $(P<0.01)$. 
cal group averaged a sample-to-positive ratio of 2.07 \pm 0.24 for serum antibody, compared with a sampleto-positive ratio of $0.17 \pm 0.10$ for cows with subclinical status. It is clear that cattle afflicted with clinical disease are unable to absorb or metabolize vitamin $\mathrm{D}_{3}$ as well as asymptomatic cattle or noninfected controls. However, hosts that are diseased may be to unable to adequately absorb nutrients from the diet efficiently. Johne's disease (paratuberculosis) is characterized by a chronic inflammation of the small intestine, a target tissue for colonization of MAP. During the clinical stage of disease, the small intestine becomes corrugated and thickened due to the influx of macrophages and lymphocytes into the region. Animals become unable to properly absorb nutrients across the thickened wall and suffer from weight loss and cachexia. As vitamin $\mathrm{D}_{3}$ is absorbed via the small intestine, it is likely that disease state would affect its uptake (Norman and Henry, 2007), which would be corroborated by the further decline in serum $25 \mathrm{OHD}_{3}$ for clinical cows at posting. Culling of noninfected control cows and subclinical cows was routinely performed due to age of animals and hip, foot, or udder problems, unassociated with the presence of infectious disease. However, culling of clinical cows was strongly associated with signs of clinical disease, including profuse diarrhea and severe weight loss. Studies in humans have demonstrated that patients suffering from disorders associated with severe inflammation, such as knee replacements, acute pancreatitis, congestive heart failure, and infections, have low serum $25 \mathrm{OHD}_{3}$ concentrations (Autier et al., 2014). Further, it has been shown that proinflammatory markers, such as tumor necrosis factor- $\alpha$ or C-reactive protein, are correlated with reduced serum $25 \mathrm{OHD}_{3}$ (Peterson and Heffernan, 2008; Murr et al., 2012). One proposed mechanism for shifts in vitamin $\mathrm{D}$ metabolism during intracellular infections is the induction of $C Y$ P2 $7 B 1$ expression by proinflammatory cytokines. Interestingly, we observed a significant $(P<0.01)$ correlation between $I F N G$ and $C Y P 27 B 1$ gene expression in this study, suggesting that upregulation of $I F N G$ is inducing CYP27B1 expression. The work of Fabri et al. (2011) would support these finding, as they observed that treatment of human monocytes with exogenous IFNG increased CYP27B1 enzymatic activity and gene expression. This results in increased conversion of $25 \mathrm{OHD}_{3}$ to $1,25(\mathrm{OH})_{2} \mathrm{D}_{3}$, which induces CYP24A. This enzyme degrades both $25 \mathrm{OHD}_{3}$ and $1,25(\mathrm{OH})_{2} \mathrm{D}_{3}$ to inactive products and decreases their half-life, ultimately resulting in lowered serum $25 \mathrm{OHD}_{3}$ (Nelson et al., 2012).

Upon absorption from the diet, vitamin D is metabolized from 7-dehydrocholesterol in the skin to form pre-vitamin $\mathrm{D}_{3}$ that isomerizes to vitamin $\mathrm{D}_{3}$. Vitamin
$\mathrm{D}_{3}$ is then hydroxylated in the liver to form $25 \mathrm{OHD}_{3}$ via the enzymes encoded primarily by microsomal CYP2R1 gene and, to a lesser extent, a mitochondrial CYP27A1 gene (Bergadà et al., 2014). The CYP27A1 gene also codes for a 27-hydroxylase enzyme associated with reduced lipid accumulation within the macrophage, thereby promoting innate defenses of the host (Quinn et al., 2005). In the present study, CYP27A1 expression was influenced by stage of disease, as expression trended higher in clinical cows and was downregulated in subclinical cows compared with controls. As the MAP organism has a high lipid content, it is probable that the accumulation of MAP in the tissue of clinically affected cows triggered the upregulation of this gene. The CYP27B1 gene that encodes the 1- $\alpha$ hydroxylase enzyme was upregulated for clinical cows compared with both subclinical cows and noninfected controls. The 1- $\alpha$ hydroxylase enzyme encoded by this gene is predominantly found in the kidney, but extrarenal sources of the enzyme also exist, including cells of the monocyte or macrophage lineage (Monkawa et al., 2000). Gene expression of CYP27B1 was induced in peripheral blood mononuclear cells from cattle vaccinated with $M$. bovis-BCG (bacillus Calmette-Guérin) upon stimulation of cells with $M$. bovis antigen (Nelson et al., 2011). Although direct measurements of $1,25(\mathrm{OH})_{2} \mathrm{D}_{3}$ have not been done in macrophages of cattle, $1,25(\mathrm{OH})_{2} \mathrm{D}_{3}$ was localized by immunohistochemistry within the granulomatous lesions of lymph nodes isolated from $M$. bovis-infected cattle (Rhodes et al., 2003). Although the cells were not defined specifically, they were determined to be mononuclear cells by morphology. Studies with humans have demonstrated that patients with active tuberculosis had significantly higher 1- $\alpha$ hydroxylase activity in monocytes than those in the frequent tuberculosis contact group (Tung et al., 2013). The local production of $1,25(\mathrm{OH})_{2} \mathrm{D}_{3}$ may be a compensatory mechanism in hosts that are diseased, increasing autocrine and paracrine activation of macrophages and associated cells.

An interesting association of increased gene expression for $V D B P$ with MAP infection, regardless of stage of disease, was observed. Previously, VDBP had been shown to be a key serum biomarker in calves experimentally infected with MAP for 12 mo (Seth et al., 2009). Another study screened serum samples from calves that were infected with $M$. bovis for various periods of time and serum $V D B P$ was found to highly sensitive and specific for $M$. bovis detection (Lamont et al., 2014). Additionally, serum VDBP levels were highly elevated in human patients with active tuberculosis, indicating this is a key marker of mycobacterial infections (Tanaka et al., 2011). Influence of disease status on IFN- $\gamma$ was 
included, as one mechanism of action for $1,25(\mathrm{OH})_{2} \mathrm{D}_{3}$ in cattle is the downregulation of this cytokine in the host (Nelson et al., 2012). The inverse relationship between IFN- $\gamma$ and serum $25(\mathrm{OH}) \mathrm{D}_{3}$ was observed only for cows in the clinical stage of disease, fitting the pattern host responses in mycobacterial infections.

In conclusion, it is clear that the stage of disease is critical to interpretation as to a role for vitamin $\mathrm{D}_{3}$ in cattle with Johne's disease. The reduction in serum $25 \mathrm{OHD}_{3}$ may be due to impedance of absorption of dietary vitamin $\mathrm{D}_{3}$ due to a thickened intestinal wall in animals with end-stage disease. In addition, a state of chronic inflammation associated with clinical disease may have also contributed to the decline. The upregulation of $C Y{ }^{2} 27 B 1$ suggests that animals in clinical status may invoke a localized compensatory mechanism to maintain immunologic function of the macrophages. This field of research is compelling and suggests that further work would be key to understanding critical mechanisms for controlling MAP infection in the host.

\section{ACKNOWLEDGMENTS}

The authors thank Derrell Hoy and Margaret Walker for their technical assistance in the laboratory.

\section{REFERENCES}

Anders, S., P. T. Pyl, and W. Huber. 2014. HTSeq-A Phython framework to work with high-throughput sequencing data. Bioinformatics 31:166-169. https://doi.org/10.1093/bioinformatics/btu638.

Autier, P., M. Boniol, C. Pizot, and P. Mullie. 2014. Vitamin D status and ill health: A systematic review. Lancet 2:76-89.

Bergadà, L., J. Pallares, M. V. Arcidiacono, A. Cardus, M. Santacana, J. Valls, G. Cao, E. Fernandez, X. Dolcet, A. S. Dusso, and X. Matias-Guiu. 2014. Role of local bioactivation of vitamin D by CYP27A1 and CYP2R1 in the control of cell growth in normal endometrium and endometrial carcinoma. Lab. Invest. 94:608-622.

Elsik, C. G., D. R. Unni, C. M. Diesh, A. Tayal, M. L. Emery, H. N. Nguyen, and D. E. Hagen. 2016. Bovine Genome Database: New tools for gleaning function from the Bos taurus genome. Nucleic Acids Res. 44:D834-D839. https://doi.org/10.1093/nar/gkv1077.

Fabri, M., S. Stenger, D. Shin, J. Yuk, P. T. Liu, S. Realegeno, H. Lee, S. R. Krutzik, M. Schenk, P. A. Sieling, R. Teles, D. Montoya, S. S. Iyer, H. Bruns, D. M. Lewinsohn, B. W. Hollis, M. Hewison, J. S. Adams, A. Steinmeyer, U. Zugel, G. Cheng, E. Jo, B. R. Bloom, and R. L. Modlin. 2011. Vitamin D is required for IFN- $\gamma$-mediated antimicrobial activity of human macrophages. Sci. Transl. Med. 3:104ra102.

Hempel, R. J., J. P. Bannantine, and J. R. Stabel. 2016. Transcriptional profiling of ileocecal valve of Holstein dairy cows infected with Mycobacterium avium ssp. paratuberculosis. PLoS One 11:e0153932. https://doi.org/10.1371/journal.pone.0153932.

Hollis, B. W., J. Q. Kamerud, S. R. Selvaag, J. D. Lorenz, and J. L. Napoli. 1993. Determination of vitamin D status by radioimmunoassay with an 125-labeled tracer. Clin. Chem. 39:529-533.

Khalifeh, M. S., and J. R. Stabel. 2013. Clinical disease upregulates expression of CD40 and CD40 ligand on peripheral blood mononuclear cells from cattle naturally infected with Mycobacterium avium ssp. paratuberculosis. Clin. Vaccine Immunol. 20:1274-1282.
Kim, D., G. Pertea, C. Trapnell, H. Pimentel, R. Kelley, and S. L. Salzberg. 2013. TopHat2: Accurate alignment of transcriptomes in the presence of insertions, deletions and gene fusions. Genome Biol. 14:R36. https://doi.org/10.1186/gb-2013-14-4-r36.

Lamont, E. A., H. K. Janagama, J. Ribeiro-Lima, L. Vulchanova, M. Seth, M. Yang, K. Kurmi, W. R. Waters, T. Thacker, and S. Sreevatsan. 2014. Circulating Mycobacterium avium bovis peptides and host response proteins as biomarkers for unambiguous detection of subclinical infection. J. Clin. Microbiol. 52:536-543.

Langmead, B., and S. L. Salzberg. 2012. Fast gapped-read alignment with Bowtie 2. Nat. Methods 9:357-359.

Li, H., B. Handsaker, A. Wysoker, T. Fennell, J. Ruan, N. Homer, G. Marth, G. Abecasic, and R. Durbin. 2009. The sequence alignment/map format and SAMtools. Bioinformatics 25:2078-2079. https://doi.org/10.1093/bioinformatics/btp352.

Lippolis, J. D., T. A. Reinhardt, R. A. Sacco, B. J. Nonnecke, and C. D. Nelson. 2011. Treatment of an intramammary bacterial infection with 25-hydroxyvitamin $\mathrm{D}_{3}$. PLoS One 6:e25479. https://doi .org/10.1371/journal.pone.0025479.

Liu, P. T., S. Stenger, H. Li, L. Wenzel, B. H. Tan, S. R. Krutzik, M. T. Ochoa, J. Schauber, K. Wu, C. Meinken, D. L. Kamen, M. Wagner, R. Bals, A. Steinmeyer, U. Zugel, R. L. Gallo, D. Eisenberg, M. Hewison, B. W. Hollis, J. S. Adams, B. R. Bloom, and R. L. Modlin. 2006. Toll-like receptor triggering of a vitamin D-mediated human antimicrobial response. Science 311:1770-1773.

Liu, P. T., S. Stenger, D. H. Tang, and R. L. Modlin. 2007. Cutting edge: Vitamin D-mediated human antimicrobial activity against Mycobacterium tuberculosis is dependent on the induction of cathelicidin. J. Immunol. 179:2060-2063.

Monkawa, T., T. Yoshida, M. Hayashi, and T. Saruta. 2000. Identification of 25-hydroxyvitamin D3 1alpha-hydroxylase gene expression in macrophages. Kidney Int. 58:559-568.

Murr, C., S. Pilz, T. B. Grammer, M. E. Kleber, A. Meinitzer, B. O. Boehm, W. Marz, and D. Fuchs. 2012. Vitamin D deficiency parallels inflammation and immune activation, the Ludwigshafen Risk and Cardiovascular Health (LURIC) study. Clin. Chem. Lab. Med. 50:2205-2212

Nelson, C. D., J. D. Lippolis, T. A. Reinhardt, R. E. Sacco, J. L. Powell, M. E. Drewnoski, M. O'Neill, D. C. Beitz, and W. P. Weiss. 2016. Vitamin D status of dairy cattle: Outcomes of current practices in the dairy industry. J. Dairy Sci. 99:10150-10160.

Nelson, C. D., B. J. Nonnecke, T. A. Reinhardt, W. R. Waters, D. C. Beitz, and J. D. Lippolis. 2011. Regulation of Mycobacterium-specific mononuclear cell responses by 25 -hydroxyvitamin D3. PLoS One 6:e21674. https://doi.org/10.1371/journal.pone.0021674.

Nelson, C. D., T. A. Reinhardt, J. D. Lippolis, R. E. Sacco, and B. J. Nonnecke. 2012. Vitamin D signaling in the bovine immune system: A model for understanding human vitamin D requirements. Nutrients 4:181-196.

Norman, A. W., and H. L. Henry. 2007. Vitamin D. Pages 47-99 in Handbook of Vitamins. 4th ed. J. Zempleni, R. B. Rucker, D. B. McCormick, and J. W. Suttle, ed. CRC Press, Boca Raton, FL.

NRC. 2001. Nutrient Requirements of Domestic Animals: Nutrient Requirements of Dairy Cattle. 7th Rev. Ed. Natl. Acad. Sci., Washington, DC.

Peterson, C. A., and M. E. Heffernan. 2008. Serum tumor necrosis factor-alpha concentrations are negatively correlated with serum $25(\mathrm{OH}) \mathrm{D}$ concentrations in healthy women. J. Inflamm. (Lond.) $5: 10$.

Prietl, B., G. Treiber, T. R. Pieber, and K. Amrein. 2013. Vitamin D and immune function. Nutrients 5:2502-2521.

Quinn, C. M., W. Jessup, J. Wong, L. Kritharides, and A. J. Brown. 2005. Expression and regulation of sterol 27-hydroxylase (CYP27A1) in human macrophages: a role for RXR and PPAR $\gamma$ ligands. Biochem. J. 385:823-830.

R Core Team. 2016. R: A Language and Environment for Statistical Computing. R Foundation for Statistical Computing, Vienna, Austria.

Rhodes, S. G., L. A. Terry, J. Hope, R. G. Hewinson, and H. M. Vordermeier. 2003. 1, 25-dihydroxyvitamin D3 and development of 
tuberculosis in cattle. 2003. Clin. Diagn. Lab. Immunol. 10:1129 1135.

Robinson, M. D., D. J. McCarthy, and G. K. Smyth. 2010. EdgeR: A bioconductor package for differential expression analysis of digital gene expression data. Bioinformatics 26:139-140. https://doi.org/ 10.1093/bioinformatics/btp616.

Robinson, M. D., and G. K. Smyth. 2007. Moderated statistical tests for assessing differences in tag abundance. Bioinformatics 23:28812887. https://doi.org/10.1093/bioinformatics/btm453.

Seth, M., E. A. Lamont, H. K. Janagama, A. Widdel, L. Vulchanova, J. R. Stabel, W. R. Waters, M. V. Palmer, and S. Sreevatsan. 2009. Biomarker discovery in subclinical mycobacterial infections in cattle. PLOS One 4:e5478. https://doi.org/10.1371/journal pone.0005478

Sorge, U. S., T. Molitor, J. Linn, D. Gallaher, and S. J. Wells. 2013 Cow-level association between serum 25-hydroxyvitamin D concentration and Mycobacterium avium subspecies paratuberculosis antibody positivity: A pilot study. J. Dairy Sci. 96:1030-1037.
Stabel, J. R. 1997. An improved method for cultivation of Mycobacterium paratuberculosis from bovine fecal samples and comparison to three other methods. J. Vet. Diagn. Invest. 9:375-380.

Tanaka, T., S. Sakurada, K. Kano, E. Takahashi, K. Yasuda, H. Hirano, Y. Kaburagi, N. Kobayashi, N. T. Hang, L. T. Lien, I. Matsushita, M. Hijikata, T. Uchida, and N. Keicho. 2011. Identification of tuberculosis-associated proteins in whole blood supernatant. BMC Infect. Dis. 11:71.

Tung, Y. C., T. T. Ou, and W. C. Tsai. 2013. Elevated 1-a hydroxylase activity in monocytes from patients with active tuberculosis Clin. Dev. Immunol. 2013:928138. https://doi.org/10.1155/2013/ 928138.

Waters, W. R., B. J. Nonnecke, T. E. Rahner, M. V. Palmer, D. L. Whipple, and R. L. Horst. 2001. Modulation of Mycobacterium bovis-specific responses of bovine peripheral blood mononuclear cells by 1,25 -dihydroxyvitamin $\mathrm{D}_{3}$. Clin. Diagn. Lab. Immunol. $8: 1204-1212$. 